\title{
Dairy farm management practices and the risk of contamination of tank milk from Clostridium spp. and Paenibacillus spp. spores in silage, total mixed ration, dairy cow feces, and raw milk
}

\author{
G. Borreani, ${ }^{*}$ F. Ferrero, D. Nucera, M. Casale, S. Piano, and E. Tabacco \\ Department of Agricultural, Forest and Food Sciences (DISAFA), University of Torino, 10095 Grugliasco (TO), Italy
}

\begin{abstract}
The occurrence of Paenibacillus and Clostridium spores in silage is of great concern for dairy producers because their spores can contaminate milk and damage processed milk and semi-hard cheeses. Spoiled silage is considered to be the main contamination source of the total mixed ration (TMR), feces of dairy cows, and consequently bulk tank milk via the contamination of cow teats by dirt during milking. The presence of an anaerobic and facultative anaerobic sporeformer population in different matrices (soil, corn silage, other feeds, TMR, feces, and milk) and its transmission pathway has been studied on 49 dairy farms by coupling plate count data with 16S-DNA identification. The different matrices have shown a high variability in the anaerobic and facultative anaerobic spore count, with the highest values being found in the aerobically deteriorated areas of corn silages. Clostridium tyrobutyricum, Paenibacillus macerans, and Paenibacillus thermophilus were detected in all the matrices. The TMR spore count was influenced by the amount of spoiled corn silage in the TMR and by the care taken when cleaning the spoiled silage before feed-out. Most of the farms that prevent the presence of visible moldy silage in the silo and carefully clean to remove molded spots were able to maintain their TMR spore counts below $4.0 \log$ spores/g. When a level of 4.5 log spores/g of TMR was exceeded, the feces presented a greater contamination than $3.0 \log$ spores/g. Moreover, the higher the number of spores in the feces was, the higher the number of spores in the milk. Most of the farms that presented a feces contamination greater than 5.0 log spores/g had a higher milk spore contamination than 1,000 spores/L. Careful animal cleaning and good milking practices have been found to be essential to maintain low levels of contamination in bulk tank milk, but it has emerged that only by coupling
\end{abstract}

Received February 11, 2019.

Accepted May 22, 2019.

*Corresponding author: giorgio.borreani@unito.it these practices with a correct silage management and cleaning during TMR preparation can the contamination of milk by spores be kept at a low level. It has been found that aerobically deteriorated silage has a great capacity to contaminate TMR and consequently to increase the risk of milk spore contamination, even when routine milking practices are adopted correctly. Key words: silage aerobic deterioration, management practice, Paenibacillus spp., Clostridium spp

\section{INTRODUCTION}

The occurrence of Paenibacillus and Clostridium spores in silage is of great concern for dairy producers because their spores can survive milk and cheese processing; thus, after germination, some strains are capable of spoiling processed milk and dairy products (te Giffel et al., 2002; Masiello et al., 2017). The ubiquitous nature of these sporeformers and the shift caused by the pasteurization processes may result in sporeformers being the dominant viable microflora, even when the total microbial count in raw bulk milk is at least 100- to 1,000-fold higher than the spore count (Wells-Bennik at al., 2016). Butyric acid fermentation in cheese (late-blowing), caused by the outgrowth of the clostridial spores present in raw milk (Klijn et al., 1995; Le Bourhis et al., 2005), which commonly originate from silage (Vissers et al., 2007c; Julien et al., 2008), can create a considerable loss of product, especially in the production of semi-hard cheeses (Stadhouders et al., 1983; Colombari et al., 2001). Several studies have reported that the initial contamination of milk with spore-forming bacteria occurs on dairy farms (Vissers et al., 2007c; Julien et al., 2008; Masiello et al., 2017) and is mainly due to the presence of spores in soil, silage, and other feeds. Spores are concentrated in the feces of dairy cows and transferred to the raw milk via the contamination of cow teats with dirt during milking (Vissers et al., 2007b). It has been shown that the high risk of sporeformer contamination of bulk tank milk could be attributable to aerobically deteriorated silages, 
which can contribute to increasing the spore contamination of TMR and consequently of cow feces (Jonsson, 1991; Vissers et al., 2007c; Driehuis et al., 2016). When the aerobic deterioration of silages takes place, oxygen penetration indirectly stimulates the growth of anaerobic microorganisms (Jonsson, 1989, 1991). Aerobic microorganisms, mainly yeasts, consume oxygen close to the surface and cause an increase in the silage temperature. Moreover, the aerobic/anaerobic zone moves toward the surface of silage exposed to air and anaerobiosis is restored in the deeper parts (Jonsson, 1989). Clostridium tyrobutyricum and other anaerobic or facultative anaerobic sporeformers (mainly clostridia and Paenibacillus spp.) can grow and multiply in this ecosystem in micro-niches with less inhibitory activity (Jonsson, 1989; Borreani et al., 2013). The increase in the anaerobic spore content of silage, due to air penetration, has been observed for whole-plant corn silage (Vissers et al., 2007a; Borreani and Tabacco, 2008), wilted alfalfa (Colombari et al., 2001), whole-plant grain sorghum (Tabacco et al., 2009), and grass silage (Jonsson, 1991; Vissers et al., 2007a). Furthermore, the multiplication of Paenibacillus spp. has also been reported in aerobically deteriorated corn (Borreani et al., 2013) and grass silages (Driehuis et al., 2016). This leads to a different distribution of spores at the silage feed-out face when aerobic deterioration takes place (Tabacco and Borreani, 2002; Vissers et al., 2007a). The improper incorporation of any deteriorated part from the top layers of the silo in the feed mixer could increase contamination of the ration with filamentous fungi and anaerobic spores (Borreani and Tabacco, 2014; Borreani et al., 2018). Borreani and Tabacco (2014) found that the anaerobic spore count in corn silage increased linearly with an increase in the mold count, thus showing that the inclusion of parts of the silage that are visually spoiled (higher mold count than $5.0 \log \mathrm{cfu} / \mathrm{g}$ ) increases the risk of worsening the spore contamination of the TMR fed to lactating dairy cows.

When dairy cows are fed with contaminated feeds or TMR, the sporeformers are concentrated in the gastrointestinal tract, due to digestive processes, and they then pass to the feces, whereby the risk of milk contamination becomes greater, especially when low hygiene practices are adopted during milking (Stadhouders and Jørgensen, 1990; Vissers et al., 2007b).

Among the clostridia that are considered of concern for milk and cheese processing, C. tyrobutyricum is the most frequently detected in late-blown cheeses, and it is considered the principal causative agent of butyric acid fermentation in cheese (Klijn et al., 1995). However, spores of other Clostridium species, such as $C$. butyricum, Clostridium beijerinckii, and Clostridium sporogenes, which occur in raw milk, have been associ- ated with butyric acid fermentation and are believed to be responsible for causing late-blowing defects (Le Bourhis et al., 2005; Driehuis et al., 2016). Spores of other clostridia, and Clostridium bifermentans, Clostridium perfringens, and Clostridium tertium in particular, have also been isolated from natural and processed cheeses and raw milk, and their role as enhancers of the late-blowing defect has been suggested (Le Bourhis et al., 2007). In the last few decades, studies have shown that many organisms that were formerly classified in the Bacillus genus actually represent several genera of the Bacilli class (Durak et al., 2006). Members of the Paenibacillus genus can survive pasteurization in spore form and are able to grow under refrigeration, thus resulting in product spoilage and limiting the shelf life of HTST pasteurized fluid milk (Ivy et al., 2012). Among the Paenibacillus spp., the most frequently reported are Paenibacillus odorifer, Paenibacillus graminis, Paenibacillus amylolyticus, Paenibacillus c.f. peoriae, and Paenibacillus polymixa in milk (Ivy et al., 2012; Driehuis et al., 2016), and P. polymyxa, Paenibacillus pabuli, and Paenibacillus macerans in silages (Borreani et al., 2013; Driehuis, 2013; Driehuis et al., 2016).

The objectives of this study were (1) to verify on farm the role of the aerobic deterioration of corn silage on the proliferation of Clostridium and Paenibacillus spores; (2) to identify, through 16S-DNA sequencing, the dominant species of anaerobic and facultative anaerobic sporeformers along the milk chain from the farm soil to the bulk tank milk; and (3) to evaluate whether careful management practices, aimed at reducing the amount of aerobic deteriorated corn silage that reaches TMR, could mitigate the carry-over of anaerobic and facultative anaerobic spores in milk.

\section{MATERIALS AND METHODS}

\section{Farm Selection and Survey Design}

A survey was carried out over a 2-yr period (20132014) in the western Po plain (Italy) on 49 dairy farms (Italian Friesian breed) that produced milk destined for Grana Padano Protected Designation of Origin (PDO) cheese. The farms were selected in agreement with the technicians from the "Consorzio di Tutela Grana Padano" to be representative of the Grana Padano production area (around 150,000 t of cheese produced in 2017 in 127 dairy plants in the Lombardia, Veneto, Piemonte, and Emilia-Romagna regions of Italy). The farms were selected on the basis of the farmers' willingness to participate in the survey, and a previous classification of the anaerobic spore levels in the bulk tank milk from a group of 156 farms that supply milk to 2 cheese factories in Lombardy (Italy), and in which 
Table 1. Summary of the surveyed management practices and samples collected during farm visits to 49 dairy farms in Lombardy (Italy)

\begin{tabular}{|c|c|c|}
\hline Factor & Description & $\begin{array}{l}\text { No. of } \\
\text { samples }\end{array}$ \\
\hline Soil & $\begin{array}{l}\text { Information: crop succession in the last } 5 \mathrm{yr} \text {; slurry and manure application rates, method, and } \\
\text { timing of the application. } \\
\text { Samples: } 5 \text { to } 10 \text { randomly selected } 0 \text { - to } 30-\mathrm{cm} \text { cores from a representative cultivated area. }\end{array}$ & 49 (soil) \\
\hline Corn silage & $\begin{array}{l}\text { Information: amount of silage consumed daily and feeding rates, filling and packing methods, } \\
\text { silo cover, materials used to hold the cover on the top of the silo surface, silo face area, visible } \\
\text { spoiled area (area visibly spoiled/face area), temperatures at the silo face according to Borreani } \\
\text { and Tabacco ( } 2010) \text {. } \\
\text { Samples: samples collected from the core (C) of the silo (pool of } 5 \text { cores), from the top close to } \\
\text { the sealant film (A1, pool of } 5 \text { grabs), from the zone immediately above the top (BA1, pool of } 5 \\
\text { grabs). }\end{array}$ & $\begin{array}{l}49(\mathrm{C}) \\
47^{1}(\mathrm{~A} 1) \\
49(\mathrm{BA} 1)\end{array}$ \\
\hline TMR & $\begin{array}{l}\text { Information: composition of the rations of dairy cows, number of distributions per day. } \\
\text { Samples: } 5 \text { to } 6 \text { randomly selected grabs, pooled to form } 1 \text { sample per farm. }\end{array}$ & 49 (TMR) \\
\hline Herd and cow hygiene & $\begin{array}{l}\text { Information: number of milking cows, average milk production per cow, average milk production } \\
\text { per year, cow hygiene score in the housing area, percent dirty of cow udders [teat cleanliness } \\
\text { scoring system: } 5=\text { clean (no visible dirt); } 4=\text { almost clean (approximately }<10 \% \text { of the area } \\
\text { dirty); } 3=\text { slightly dirty ( } 10 \text { to } 20 \% \text { of the area dirty); } 2=\text { dirty ( } 20 \text { to } 50 \% \text { of the area dirty); } \\
\text { and } 1=\text { extremely dirty ( }>50 \% \text { of the area dirty)] on } 10 \% \text { milking cows randomly selected in } \\
\text { the housing area. } \\
\text { Samples: feces from } 10 \% \text { milking cows randomly selected from the herd and pooled. }\end{array}$ & 49 (feces) \\
\hline
\end{tabular}

${ }^{1}$ Two farms did not present any visible molded area.

MPN spores are tested monthly. All the farmers were fully informed about the design of the experiment, the nature of the data being collected, and their future use. A detailed questionnaire (with questions on feed production and management practices) was presented to the farmers on each farm and the information collected on each farm is summarized in Table 1.

\section{Sample Preparation and Analyses}

The number of sub-samples and resulting pooled samples collected on the farms are reported in Table 1.

The corn silages used in the lactating cow rations at the time of the visits were sampled on each farm. Samples were collected from 3 areas in each silo: the core, at least $1 \mathrm{~m}$ from the surface $(\mathrm{n}=49)$; and 2 peripheral areas, close to the sealant film (A1), the outermost $0.15 \mathrm{~m}$ of visibly spoiled silage, which is usually discarded by farmers before feeding $(\mathrm{n}=47$, since 2 farms did not present any visible molded area); and below A1 (BA1, 0.15 to $0.30 \mathrm{~m}$ immediately below the A1 layer, which is always fed to dairy cows; $\mathrm{n}=49$ ). The samples were collected using a sterile corer (45 $\mathrm{mm}$ diameter; $250 \mathrm{~mm}$ depth) in the core area (mixing 5 randomly collected samples) and by means of 5 hand grabs (around $100 \mathrm{~g}$ ) in the A1 and BA1 sections. The temperature was measured at each sampling point of the silo to a depth of $200 \mathrm{~mm}$ (Borreani and Tabacco, 2010) using a probe thermometer. The working face area that was visibly molded/spoiled was also determined and measured to calculate the percentage of the working face that was aerobically deteriorated. Each silo was then inspected to determine whether the aerobically deteriorated silage that was discarded before silage was included in the TMR, and the farms were classified into 3 categories (farms on which deteriorated silage was not, partially, or well discarded). Farm silage were assigned to each class following these assumptions: well-discarded silage $=$ no visible spoiled silage was included in the TMR; partially $=$ some traces of spoiled silage were included in the TMR; not discarded $=$ most of the spoiled silage present in the outer layer still remained and was included in TMR. The resulting TMR fed to the lactating cows was collected immediately after unloading ( 5 to 6 sub-samples of about 200 $\mathrm{g}$, pooled in one farm sample; $\mathrm{n}=49$ ). Other feeds were also sampled if their incidence in the TMR was higher than $20 \%$ on a DM basis $(\mathrm{n}=46$, of which 19 were commercial mixes, 14 were corn grain meals, 1 was a soybean meal, and 12 were grass or alfalfa hays).

Five to 10 random soil sub-samples $(0-300 \mathrm{~mm})$ were collected on each farm and pooled into one composite soil sample, which was representative of where corn silage was grown $(n=49)$. Feces from a random $10 \%$ of lactating cows were collected and pooled into one farm sample $(\mathrm{n}=49)$. A pooled drinking and cleaning water sample was collected from the farm taps $(\mathrm{n}=49)$. One milk sample $(1 \mathrm{~L})$ from the farm bulk tank was also 
collected after 15 min of continuous mechanical mixing on each farm $(\mathrm{n}=49)$.

Each corn silage was analyzed for its chemical, microbial, and fermentative characteristics, whereas the other feeds, TMR, feces, soil, bulk tank milk, and water were only analyzed for anaerobic and facultative anaerobic sporeformers.

Each silage sample was mixed thoroughly and divided into 3 sub-samples. The first sub-sample was analyzed to determine the DM concentration, which was achieved by oven drying the sample at $65^{\circ} \mathrm{C}$ until constant weight was reached.

Thirty grams of the second wet silage sub-sample was transferred to a sterile homogenization bag, suspended 1:10 wt/vol in a peptone physiological salt solution ( $1 \mathrm{~g}$ of neutralized bacteriological peptone and $9 \mathrm{~g}$ of sodium chloride per liter), and homogenized for $4 \mathrm{~min}$ in a laboratory Stomacher blender (Seward Ltd., London, UK) for the microbial counts. The mold and yeast counts were determined by preparing serial dilutions and using the pour plate technique with $40.0 \mathrm{~g} / \mathrm{L}$ of yeast extract glucose chloramphenicol agar (YGC agar, Difco, West Molesey, Surrey, UK). Petri dishes were incubated at $25^{\circ} \mathrm{C}$ for 3 and $5 \mathrm{~d}$ for yeast and mold, respectively, and then the mold and yeast colony-forming units were enumerated separately on plates that yielded 1 to $100 \mathrm{cfu}$ per Petri dish. The mold and yeast colonyforming units were enumerated separately, according to their macro-morphological features. The anaerobic and facultative anaerobic spores were counted after pasteurization of the serial dilutions at $80^{\circ} \mathrm{C}$ for $10 \mathrm{~min}$ to inactivate vegetative cells and to trigger the germination of spores, and this was followed by the streak plate technique, which was conducted with $50.0 \mathrm{~g} / \mathrm{L}$ of reinforced clostridial medium agar (RCM; SigmaAldrich, Merck KGaA, Darmstadt, Germany), 0.005\% of neutral red (Sigma-Aldrich, Merck KGaA), and 200 $\mathrm{mg} / \mathrm{kg}$ of D-cycloserine (Sigma-Aldrich, Merck KGaA) incubated anaerobically for $7 \mathrm{~d}$ at $35^{\circ} \mathrm{C}$ (Jonsson, 1990). Colonies showing evidence of gold-yellow fluorescence under UV light were considered for identification.

Thirty grams of the third wet silage sub-sample was transferred to a homogenization bag, suspended 1:10 wt/vol in deionized water, and homogenized for $4 \mathrm{~min}$ in a laboratory Stomacher blender for quantification of the $\mathrm{pH}$ value and nitrate content. The $\mathrm{pH}$ value was determined through the use of specific electrodes. The nitrate content was determined in the water extract, through semiquantitative analysis, using Merckoquant test strips (Merck KGaA; Borreani and Tabacco, 2008).

About $50 \mathrm{~g}$ of the same sub-sample was homogenized and extracted for $4 \mathrm{~min}$ in a Stomacher blender in $\mathrm{H}_{2} \mathrm{SO}_{4} \quad 0.05 \quad M$ at an acid-to-sample material (fresh weight) ratio of 5:1. The solution was filtered with a $0.20-\mu \mathrm{m}$ syringe filter and used for quantification of the lactic and monocarboxylic acids (acetic, propionic, and butyric acids) with an HPLC (Agilent Technologies, Santa Clara, CA; Canale et al., 1984). Ethanol and 1,2-propanediol were determined by means of HPLC, coupled to a refractive index detector, on an Aminex HPX-87H column (Bio-Rad Laboratories, Richmond, CA). The analyses were performed isocratically under the following conditions: mobile phase $0.0025 \mathrm{M} \mathrm{H}_{2} \mathrm{SO}_{4}$, flow rate $0.5 \mathrm{~mL} / \mathrm{min}$, column temperature $37^{\circ} \mathrm{C}$, and injection volume $100 \mu \mathrm{L}$. Duplicate analyses were performed for all the determined parameters.

Anaerobic and facultative anaerobic spores of the farm soils, other feeds, TMR, feces, water, and tank milk were measured and identified, as reported for the silage samples. The detection limit of the anaerobic and facultative anaerobic spores in the silage, TMR, soil, and feces was 50 spores/g and it was 62 spores/L in the milk. To improve the detection limit of milk collected on farms with low levels of spores, $40 \mathrm{~mL}$ of milk was centrifuged $\left(3,600 \times g\right.$ for $15 \min$ at $\left.20^{\circ} \mathrm{C}\right)$, the supernatant was removed, and the resultant pellet was re-suspended in $1 \mathrm{~mL}$ of a peptone physiological salt solution, in Eppendorf vials (Eppendorf AG, Hamburg, Germany), and re-centrifuged $(17,980 \times g$ for 3 min at $20^{\circ} \mathrm{C}$ ). The pellet was then re-suspended in $0.5 \mathrm{~mL}$ of a peptone physiological salt solution, which was plated onto $2 \mathrm{RCM}$ streak plates [ 1 colony in $0.2 \mathrm{~mL}$ (2 plates), and this resulted in a detection limit of 62 spores/L].

The milk fat, protein, lactose, urea, and casein contents were measured on a subsample by means of Fourier transform infrared spectroscopy (MilkoScan FT6000, Foss Electric A/S, Hillerød, Denmark). The SCC and total bacteria counts were automatically determined in the same subsamples by the mean of Fossomatic FC (Foss Electric A/S) and BactoScan FC (Foss Electric A/S), respectively.

\section{Bacterial Isolation and Identification}

Up to 6 yellow colonies were selected from each sample by visually identifying and picking out the distinct morphologies. Up to 10 colonies were selected in the milk with more than 1,000 spores/L. Each colony was purified by streaking on RCM agar and subsequently incubated for $7 \mathrm{~d}$ at $37^{\circ} \mathrm{C}$ under anaerobiosis. Phenotypic characterization was performed by conducting routine laboratory tests, and the isolates were analyzed by observing the colony morphology, Gram staining, the ability to grow anaerobically on RCM, and the presence of spores. Only gram-positive, obligate anaerobic, or facultative anaerobic endospore forming isolates were then studied in detail. Pure cultures were grown in BHI broth (Merck KGaA) for $7 \mathrm{~d}$ at $37^{\circ} \mathrm{C}$ under anaerobiosis 
before freezing in $20 \%$ glycerol at $-80^{\circ} \mathrm{C}$. The cultures were grown in BHI for $7 \mathrm{~d}$ in anaerobic chambers (Anaerocult Kit, Biomerieux, Milan, Italy) and the DNA was then extracted following the extraction kit procedures (Ultra Clean Microbial Isolation Kit, Mo Bio Laboratories Inc., Cabru, Milan, Italy). Genomic DNA was amplified using $16 \mathrm{~S}$ universal primers (527 bp), according to the manufacturer's instructions (Micro seq 500 16S rDNA Bacterial Sequencing Kit). The used primers, that is, primer sequence 5 '-TGGAGAGTTTGATCCTGGCTCAG-3' and reverse primer sequence 5'-TACCGCGGCTGCTGGCAC-3', have already been published by Hall et al. (2003). The PCR reactions were performed using a TGradient thermal cycler (VWR, Milan, Italy). Each $25 \mu \mathrm{L}$ of PCR reaction contained $2.5 \mu \mathrm{L}$ of DNA template (50 ng), $200 \mathrm{mM}$ deoxynucleotide triphosphate, $5 \mu \mathrm{L}$ of $10 \mathrm{X}$ buffer (Taq DNA Polymerase, Qiagen, Chatsworth, CA), $0.7 \mathrm{mM}$ primer, and 1.0 U of Taq DNA Polymerase (Qiagen). The PCR program was $95^{\circ} \mathrm{C}, 3 \mathrm{~min} ; 34$ cycles: $94^{\circ} \mathrm{C}, 15 \mathrm{~s} ; 55^{\circ} \mathrm{C}$, $45 \mathrm{~s} ; 72^{\circ} \mathrm{C}, 55 \mathrm{~s}$; and a final extension at $72^{\circ} \mathrm{C}$ for $7 \mathrm{~min}$. A $10-\mu \mathrm{L}$ aliquot of the PCR products from each reaction was electrophoresed in 1.5\% agarose gel and then stained with SYBR SAFE (Invitrogen, Eugene, OR). Gel images were acquired using a Gel Doc 1000 System (Bio-Rad Laboratories, Hercules, CA). The amplifications generated by $16 \mathrm{~S}$ rDNA PCR were purified and then sent to an external laboratory (IGA Technology Services, Udine, Italy) for sequencing. The obtained chromatograms were visually inspected for the absence of background noises, and only sequences with clear and unambiguous peaks were used for the subsequent analysis steps. Any areas of the sequence characterized by unresolved peaks were removed from the analysis. The generated sequences were compared with those present in the GenBank database, using BLASTn sequence similarity searching [https://blast.ncbi.nlm .nih.gov/Blast.cgi; ribosomal RNA sequences (bacteria and archaea)]. The highest identity was selected as the identified species or genus when sequence similarity was $\geq 98 \%$ (with no gaps). A match was considered appropriate when the query sequence only matched the selected level of one bacterial species. If more species matched at the same similarity level, identification was not considered to have been achieved at the species level, but only at the genus level.

\section{Statistical Analysis}

The microbial counts were $\log _{10}$ transformed and were presented on a wet weight basis. The values below the detection limit (that is, 50 spores/g in the soil, silage, TMR, and feces, and 62 spores/L in the milk) were assigned a value corresponding to half of the detection limit to calculate the average value.

The data were analyzed for their statistical significance, via ANOVA, with their significance reported at a 0.05 probability level, using the General Linear Model of the Statistical Package for Social Science (v 25.0, SPSS Inc., Chicago, IL) with the following statistical model: $Y_{\mathrm{ij}}=\mu+\alpha_{\mathrm{i}}+\varepsilon_{\mathrm{ij}}$, where $\mathrm{Y}_{\mathrm{ij}}=$ observation, $\mu=$ overall mean, $\alpha_{i}=$ the corn silage spore content (low, medium, high) or management practices (well, partially, or not discarded molded silage), and $\varepsilon_{\mathrm{ij}}=$ error. When the calculated values of $F$ were significant, the Tukey post-hoc test $(P<0.05)$ was used to interpret any significant differences among the mean values. Pearson correlation coefficients of the milk spores, percentage of molded silo face, TMR spores, feces spores, and animal cleaning score, and their level of significance were determined for each management practice (well, partially, or not discarded molded silage).

\section{RESULTS}

\section{Farm Characteristics}

The number of lactating cows per farm ranged from 16 to 301 (mean value of 105 cows) and the main cow breed was Holstein. All the farms milked twice daily, as reported in the production disciplinary regulations for Grana Padano PDO cheese. Cows were housed in freestalls $(77 \%)$ or tiestalls $(23 \%)$. The average milk production across farms was $8,400 \mathrm{~kg}$ per cow per year and ranged from 4,150 to $10,970 \mathrm{~kg}$. The utilized agricultural area of the surveyed farms ranged from 8 ha to 208 ha (mean value of 48 ha). The milk intensity reported as the fat- and protein-corrected milk produced per hectare of utilized agricultural area was on average $24 \mathrm{t} / \mathrm{ha}$, with values ranging from 4 to $61 \mathrm{t}$ of fat- and protein-corrected milk/ha. All the farms included corn silage in their milking cow TMR. The average inclusion was $33 \%$ on a DM basis, with values ranging from 9 to $49 \%$ of the DMI. Some farms $(\mathrm{n}=14)$ had other silages (e.g., sorghum silages, Italian ryegrass silage), but they used them exclusively for replacement heifer feeding.

\section{Anaerobic and Facultative Anaerobic Sporeformers Isolated in Different Matrices}

The anaerobic and facultative anaerobic sporeformer counts (log spores/g) in the soil, corn silage, other feeds, TMR, and feces of the 49 surveyed dairy farms are reported in Figure 1. The spore content was below the detection limit in all the drinking and cleaning water samples. The soil spore content had a median value of around $2.9 \log$ spores/g, with $50 \%$ of the samples 
ranging from 2.7 to $4.1 \mathrm{log}$ spores/g. The core area of the corn silages had a median spore count of 2.6 $\log$ spores/g, with $75 \%$ of the samples below $3.4 \log$ spores/g. The peripheral samples, that is, BA1 and A1, had median values of 4.8 and $6.0 \mathrm{log}$ spores/g, respectively, with only $25 \%$ of the samples being below 3.8 and $5.3 \mathrm{log}$ spores/g. Other feeds included in the ration of lactating cows presented average spore counts of 1.98 \pm 0.40 and $2.06 \pm 0.48 \log$ spores/g for dry forages (hays and straw) and concentrates (corn grain, soybean meal, and commercial mixes), respectively. The TMR had a median value of $4.3 \mathrm{log}$ spores/g, with $50 \%$ of the samples ranging from 3.9 to $5.0 \mathrm{log}$ spores $/ \mathrm{g}$. Feces showed a similar box plot to that of TMR, but with slightly lower values, and with a median value of 3.8 $\log$ spores/g.

Overall, the dominant species of anaerobic and facultative anaerobic sporeformers identified in the different matrices belonged mainly to the Clostridium and Paenibacillus genera. All the identified species and their number are reported in Table 2, where they are clustered according to the different studied matrices (soil, corn silage, other feeds, TMR, feces, and bulk tank milk). Overall, 26 species of Clostridium and 12 species of Paenibacillus were found among the studied matrices. Furthermore, Bacillus spp., Brevibacillus spp., and Lysinibacillus spp. were also identified as facultative anaerobic bacteria. Clostridium tyrobutyricum, P. macerans, and Paenibacillus thermophilus were observed in all of the matrices. Five species of clostridia (C. tyrobutyricum, C. sporogenes, Clostridium aerotolerans, Clostridium celerecrescens, and Clostridium xylanolyticum) and 2 species of Paenibacillus (P. macerans and $P$. thermophilus) were found in at least 4 matrices. Twelve species of clostridia and 4 of Paenibacillus were found in the corn silage.

\section{Spore Population in Farm Soils}

Figure 2 reports the distribution of the dominant species found in the soil, corn silage, other feeds, TMR, and feces. The anaerobic and facultative anaerobic spore-forming population of the soils was made up of $49 \%$ of clostridia species and $30 \%$ of Paenibacillus species. Of the dominant species, C. tyrobutyricum, $C$. aerotolerans, C. celerecrescens, $P$. macerans, and $P$. thermophilus presented higher frequencies than $5 \%$.

\section{Spore Population in Corn Silages}

The corn silage samples were split, in relation to their anaerobic and facultative anaerobic spore-former contents, into 3 classes: low spore contamination (below 3.0 $\log$ spores/g), medium spore contamination (between

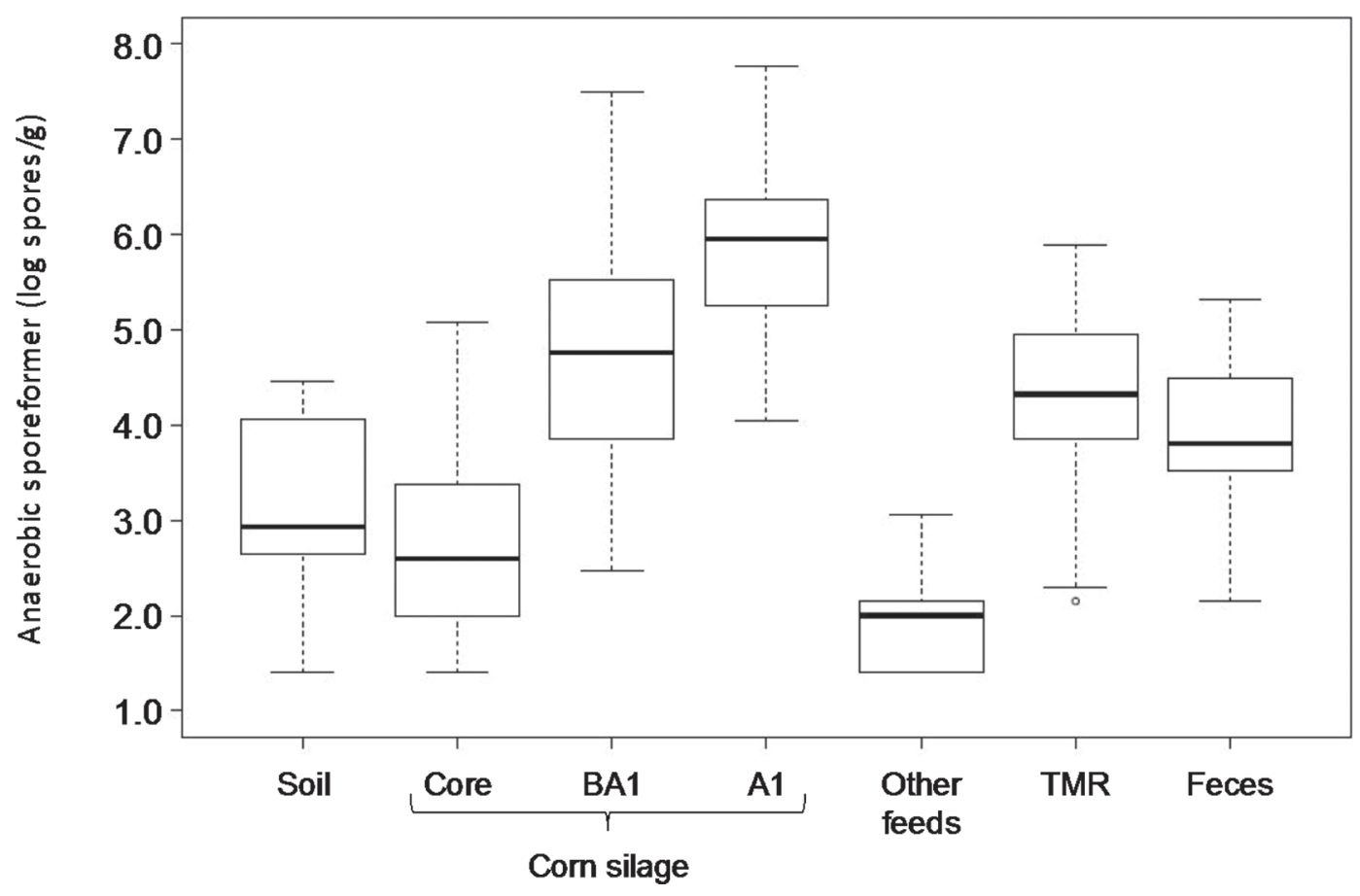

Figure 1. Box plot of the anaerobic and facultative anaerobic spore-forming bacteria of the soil, corn silage, other feeds, TMR, and feces of the 49 commercial dairy farms. Boxes $=$ interquartile range; bold line $=$ median; whiskers $=$ minimum and maximum values; dots $=$ outliers. $\mathrm{A} 1=$ silo peripheral areas close to the sealant film; $\mathrm{BA} 1=$ below $\mathrm{A} 1$. 
Table 2. Number of isolates of the predominant anaerobic and facultative anaerobic spores from farm soil, corn silage, other feeds, TMR, feces, and tank milk ${ }^{1}$

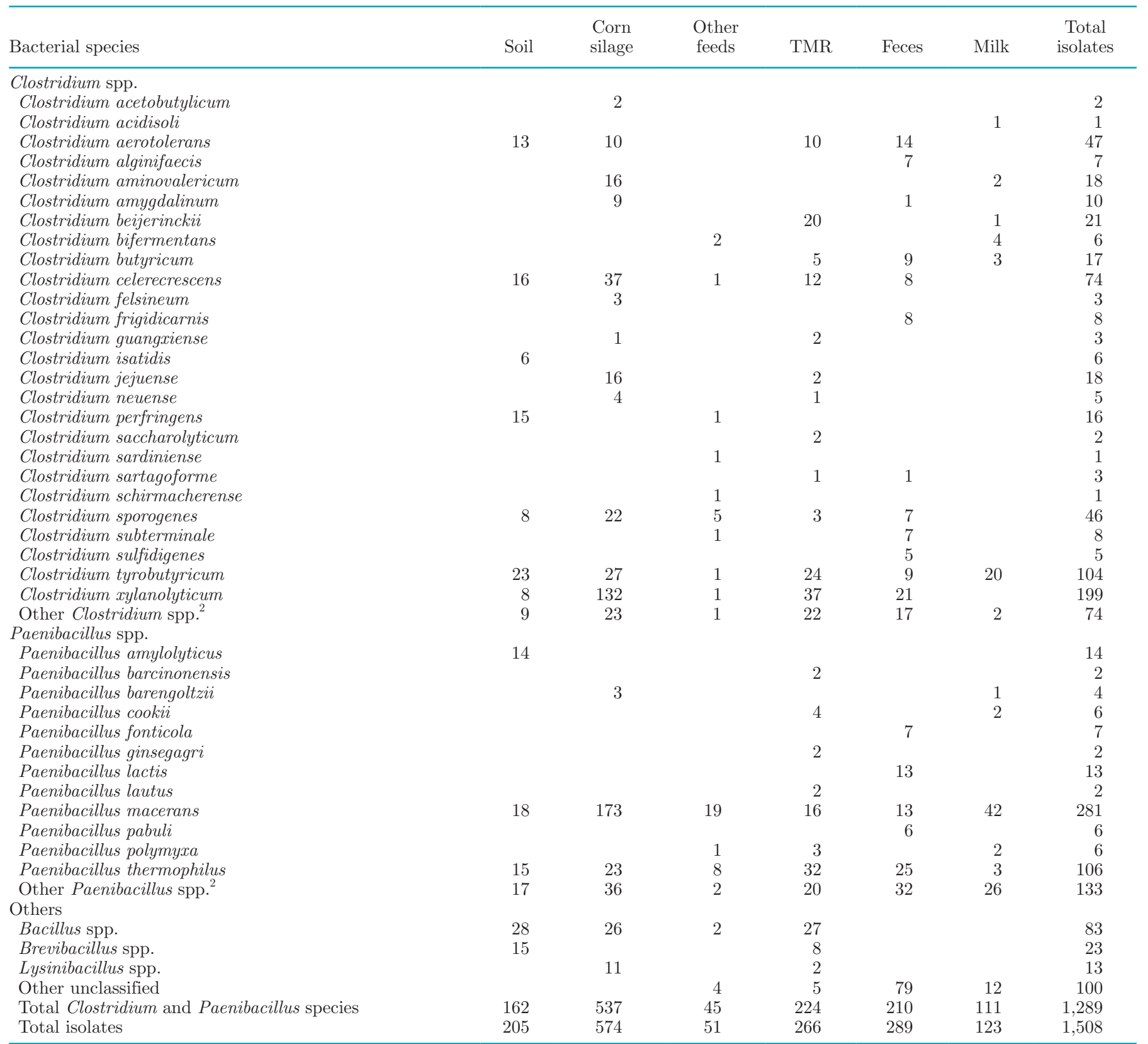

${ }^{1}$ The species were identified by means of $16 \mathrm{~S}$ universal primers when sequence similarity was $\geq 98 \%$ in the GenBank database, using BLASTn sequence similarity searching (https://blast.ncbi.nlm.nih.gov/Blast.cgi).

${ }^{2}$ Other Clostridium and Paenibacillus species that were not possible to classify at the species level.

3.0 and $5.0 \log$ spores/g), and high spore contamination (above $5.0 \mathrm{log}$ spores/g). The mean fermentative and microbial characteristics of the 3 silage classes were reported in Table 3. The low contaminated silages are mainly constituted by core silages (89.5\%), and to a lesser extent by BA1 silages (10\%); no silage collected from the A1 zone was present in this class. Most of the silages in the highly contaminated silage class were collected in the peripheral areas of the silo (34.5 and $63.8 \%$ from BA1 and A1, respectively), whereas only one sample was from the silage core. The fermentative characteristics of the low contaminated silages were typical of well-fermented lactic acid silages, with a low incidence of butyric acid (only 2 samples had a higher concentration than $1 \mathrm{~g} / \mathrm{kg}$ of DM), whereas the medium and high spore contamination silage classes presented 
higher numbers of samples containing butyric acid, with 3 samples (one from A1 and 2 from BA1) having a higher butyric acid content than $10 \mathrm{~g} / \mathrm{kg}$ of DM. Most of the medium and highly contaminated silages presented the typical fermentative profiles of aerobic deteriorated silages, with mean temperatures above $30^{\circ} \mathrm{C}$, higher values of $\mathrm{pH}$, yeast, and mold counts than the low contaminated silages, and low concentrations of fermentative products inhibiting the spoilage microorganisms (lactic and acetic acids and ethanol). Nitrates were present in $32 \%$ of the low contaminated silages, whereas a lower frequency ( $9.6 \%$ of the samples) was observed in the medium and highly contaminated samples.

The dominant clostridia found in the corn silages were C. tyrobutyricum, C. aerotolerans, Clostridium aminovalericum, C. celerecrescens, Clostridium jejuense, $C$. sporogenes, and C.xylanolyticum, whereas the Paenibacillus species were $P$. macerans, $P$. thermophilus, and $P$. cookii. Six species (C. tyrobutyricum, C. sporogenes, $C$. celerecrescens, C. xylanolyticum, $P$. macerans, and $P$. thermophilus) were present in all the zones of the silages (data not shown). The low contaminated silages were characterized by 5 dominant clostridia species, with $C$. xylanolyticum representing $38 \%$ of the total population. Clostridium tyrobutyricum, C. sporogenes, C. aerotolerans, and $C$. celerecrescens were observed, but at lower frequencies. Paenibacillus macerans was the main species of this genus and represented $25 \%$ of the total anaerobic and facultative anaerobic sporeformers of the low contaminated silages. The medium contaminated silages presented greater frequencies of $C$. celerecrescens and $P$. macerans than the lower contaminated silages. Clostridium tyrobutyricum and C. sporogenes increased in frequency in the highly contaminated silages, whereas the frequency of C. xylanolyticum decreased from $40 \%$ in the medium contaminated silages to $3 \%$.

\section{Spore Populations in Other Feeds, TMR, and Feces}

The spore content of the other feeds ranged from 1.40 to $3.06 \log$ spores/g. The dominant population was represented by the Paenibacillus genus (67\%) and the Clostridium genus (33\%). The most frequently detected dominant species were P. macerans (42\%), $P$. thermophilus (18\%), and C. sporogenes (11\%).

The TMR spore counts ranged from 2.11 to $5.89 \mathrm{log}$ spores/g. Moreover, 5 farms presented a TMR of below $3.0 \mathrm{log}$ spores/g, 34 farms a TMR of 3.0 to $5.0 \mathrm{log}$ spores/g, and 10 farms a greater TMR than $5.0 \mathrm{log}$ spores/g.

The distribution of the dominant species for the TMR contamination level was divided into 3 classes [as suggested in previous works by Stadhouders and Jørgensen (1990) and Stadhouders and Spoelstra (1990)]: a low spore contamination below $3.0 \log$ spores/g, a medium spore contamination between 3.0 and $5.0 \log$ spores/g, and a high spore contamination above 5.0

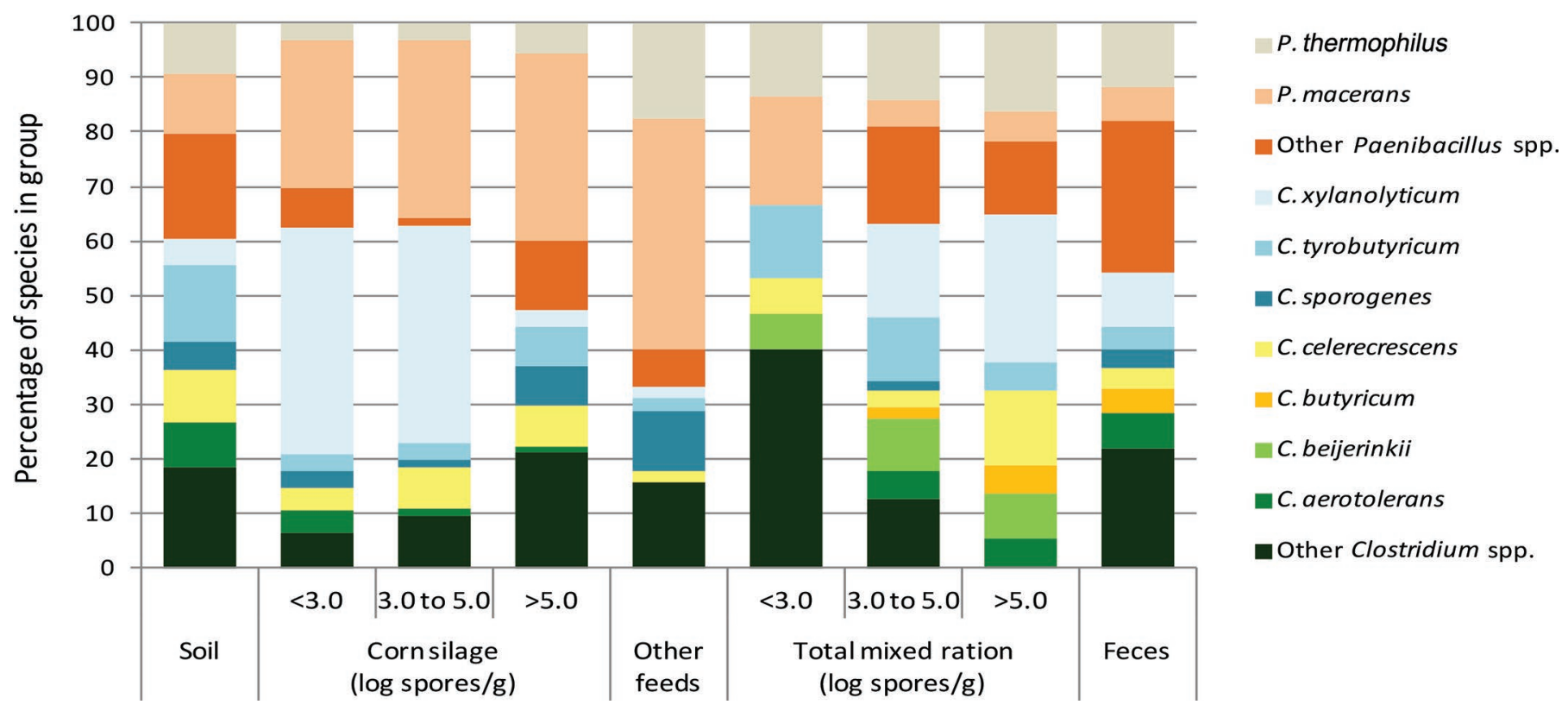

Figure 2. Distribution of the dominant anaerobic and facultative anaerobic spore-forming bacteria isolates in the soil, corn silages (divided into 3 contamination classes), other feeds, TMR (divided into 3 contamination classes), and feces of the 49 commercial dairy farms in northern Italy. 
ANAEROBIC SPOREFORMERS ON DAIRY FARMS

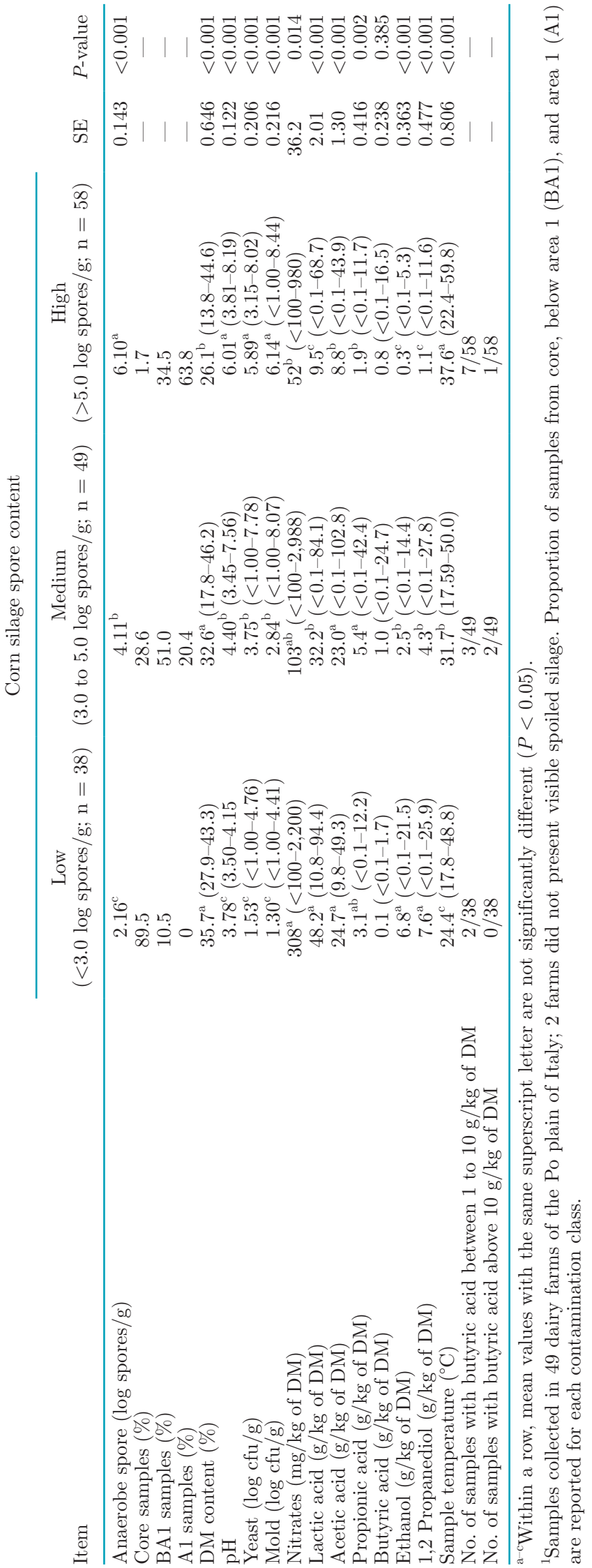


log spores/g (Figure 2). Clostridia represented 63, 54, and $52 \%$ and Paenibacillus spp. 19, 17, and $19 \%$ of the total anaerobic and facultative anaerobic sporeformers for the 3 contamination classes, respectively. The dominant species of the low contaminated TMR were $C$. tyrobutyricum, $C$. beijerinckii, and $P$. macerans. A greater variability of the dominant species was observed in the medium and high contamination classes. Clostridium xylanolyticum, C. tyrobutyricum, and P. thermophilus had frequencies that were greater than or equal to $10 \%$ in the medium contamination class, and C. aerotolerans, C. beijerinckii, C. celerecrescens, C. butyricum, $C$. sporogenes, and $P$. macerans were present at lower frequencies. Clostridium xylanolyticum, C. celerecrescens, and P. thermophilus had greater frequencies than $10 \%$ in the high contamination class, and C. aerotolerans, $C$. beijerinckii, C. butyricum, and C. tyrobutyricum were present at lower frequencies.

The spore contamination of the feces ranged from 2.15 to $5.32 \log$ spores/g. The anaerobic and facultative anaerobic spore-forming population of the feces was represented by $39 \%$ of the clostridia species and $33 \%$ of the Paenibacillus species. Clostridium xylanolyticum, $C$. aerotolerans, $P$. macerans, and $P$. thermophilus presented higher frequencies than $5 \%$ in the dominant species (Figure 2). Clostridium aerotolerans, C. celerecrescens, C. beijerinckii, C. butyricum, and C. tyrobutyricum were present at lower frequencies.

\section{Spore Population in Bulk Tank Milk}

The milk samples ranged from $<1.79$ to $3.82 \mathrm{log}$ spores/L, with a median value of $1.79 \log$ spores/L. The milk samples were split, in relation to the spore contamination level, into 3 classes: low spore contamination (below 200 spores/L); medium spore contamination (between 200 and 1,000 spores/L); and high spore contamination (above 1,000 spores/L). These classes represented 2 critical contamination levels that could influence the hard cheese making process: without any additive $<200$ spores/L (Bottazzi and Battistotti, 1978; Bergère and Sivelä, 1990) or with additives (nitrates or lysozyme) $>1,000$ spores/L (Walstra et al., 2005). The farms were distributed into classes as follows: 35 farms $<200$ spores/L (of which 20 farms were below 62 spores/L), 8 farms between 200 and 1,000 spores/L, and 6 farms $>1,000$ spores/L.

Among all the spore-forming species in the milk, clostridia represented 36,58 , and $0 \%$ of the 3 classes, respectively. The dominant anaerobic and facultative anaerobic sporeformers of the bulk tank milk are reported in Figure 3. The most frequently identified species in the low- and medium-contaminated milk was C. tyrobutyricum, whereas no clostridia were found as

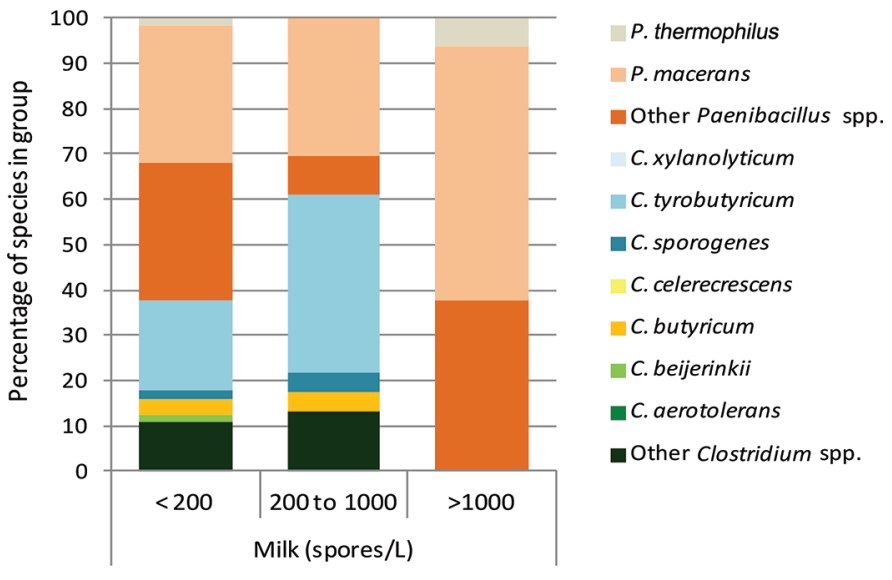

Figure 3. Distribution of the dominant anaerobic and facultative anaerobic spore-forming bacteria in the tank milk (divided into 3 contamination classes) of the 49 commercial dairy farms in northern Italy.

the dominant species in the highly contaminated milk. Clostridium butyricum, C. beijerinckii, and C. sporogenes were present at lower frequencies. The Paenibacillus species represented 60,38 , and $100 \%$ in the milk of the 3 contamination classes, respectively. Paenibacillus macerans and $P$. thermophilus were the most frequently identified species.

\section{Spore Contamination Pathway from Silage to Tank Milk}

The scatter plot of the TMR spore count and the visibly molded silo face, as affected by the different management practices adopted to discard deteriorated silage, is reported in Figure 4. The higher the presence of moldy areas in the silage was, the higher the anaerobic and facultative anaerobic spore count in the TMR. Four out of 15 farms that managed aerobic deterioration in corn silage well were found to be able to keep the TMR spore count below $3.0 \mathrm{log}$ spores/g, whereas the other farms that managed the aerobic deterioration of silage well (reduced aerobic spoiled silage and good cleaning/discarding of the spoiled part, if present) were always below $5.0 \log$ spores/g. Farms that did not carry out an effective aerobic deterioration management or cleaning of the silo before feed-out always presented higher TMR spore counts than 3.0 log spores/g, with 18 of 22 farms having higher spore counts than 4.0 log spores/g, and the highest contamination level reaching $5.89 \log$ spores/g.

The scatter plot of the anaerobic and facultative anaerobic spore count in the TMR and of the spores in the feces is reported in Figure 5. The higher the spore count in TMR is, the higher the spore count in the feces. Most of the farms that did not manage corn 


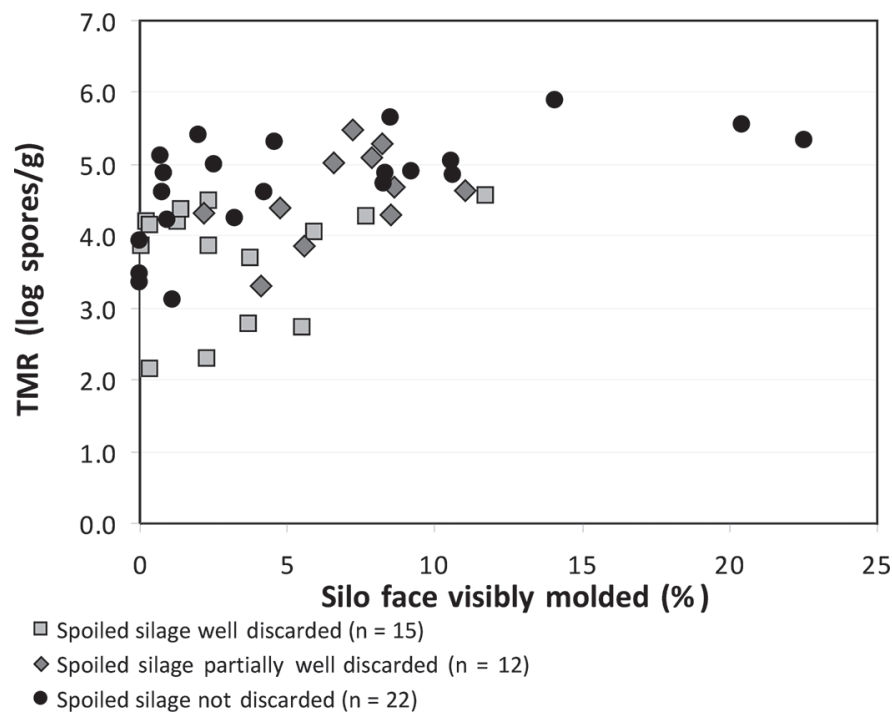

Figure 4. Scatter plot of the anaerobic and facultative anaerobic sporeformers in the TMR and the percentage of visible aerobic deteriorated corn silage fed to the dairy cows on the 49 commercial dairy farms in northern Italy, in relation to the silage management practices before feed-out.

silage in an appropriate way presented higher levels of spores in both the TMR and feces, but a lower TMR spore count did not always implicate a low spore count in the feces.

A scatter plot of the anaerobic and facultative anaerobic spore count in the feces and in the milk is reported in Figure 6. The higher the spore count in the feces is, the higher the spore count in the milk. When feces

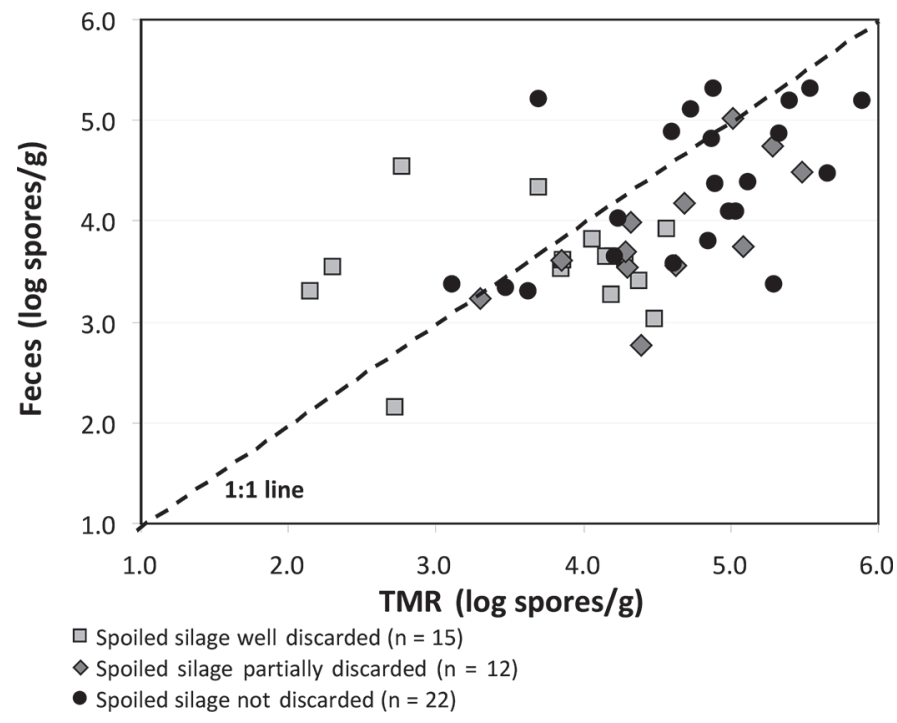

Figure 5. Scatter plot of the anaerobic and facultative anaerobic sporeformers in the TMR and feces of the 49 commercial dairy farms in northern Italy, in relation to the silage management practices before feed-out. The dotted line is the 1:1 line.

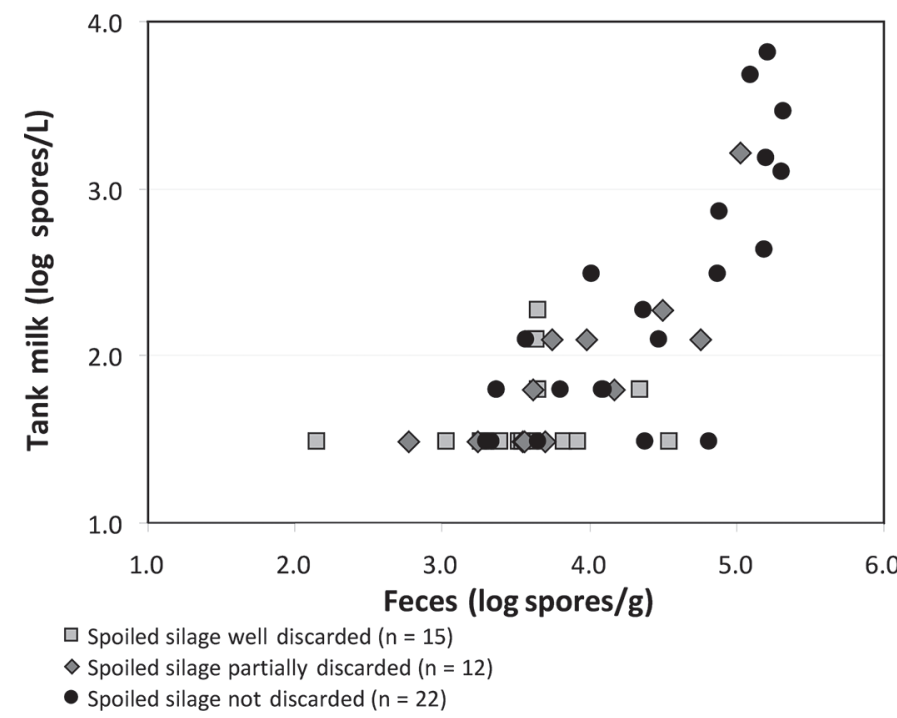

Figure 6. Scatter plot of the anaerobic and facultative anaerobic sporeformers in the feces and milk of the 49 commercial dairy farms in northern Italy, in relation to the silage management practices before feed-out.

contamination was greater than $5.0 \log$ spores/g, most of the farms presented milk spore counts greater than $3.0 \mathrm{log}$ spores/L (6 out of 7 farms). Farms with bulk tank milk spore counts greater than $3.0 \mathrm{log}$ spores/L had generally not managed their silages well.

The practical management practices applied on farm that contribute to the safety of the entire milk chain, from the feed production in the field to the milking routine, are summarized in Table 4 . Farms were divided into 3 groups according to their silage management practices (well, partially, or not discarded molded silage), and the proportion of farms applying each of the selected management practices in each group was calculated accordingly. The farms that discarded molded silages well before feeding had a lower spore count in the TMR, feces, and milk compared with those that partially or did not discard molded silages. Farms that did not discard silages before feed-out usually adopted fewer silage and milking management practices (accurate silo covering, number of films to cover the silo top, the use of film on the silo walls, pre-dipping treatments, treatments with additive) than those that discarded molded silages partially or totally.

The Pearson correlation coefficients of the spore contamination of the milk and visibly molded silo face, the spore contamination of the TMR and feces, and the hygienic score on farms that used well, partially, or not discarded corn spoiled silage before TMR preparation are reported in Table 5. The spore count in the milk of farms that did not discard molded silages before TMR preparation was positively correlated with the percent- 


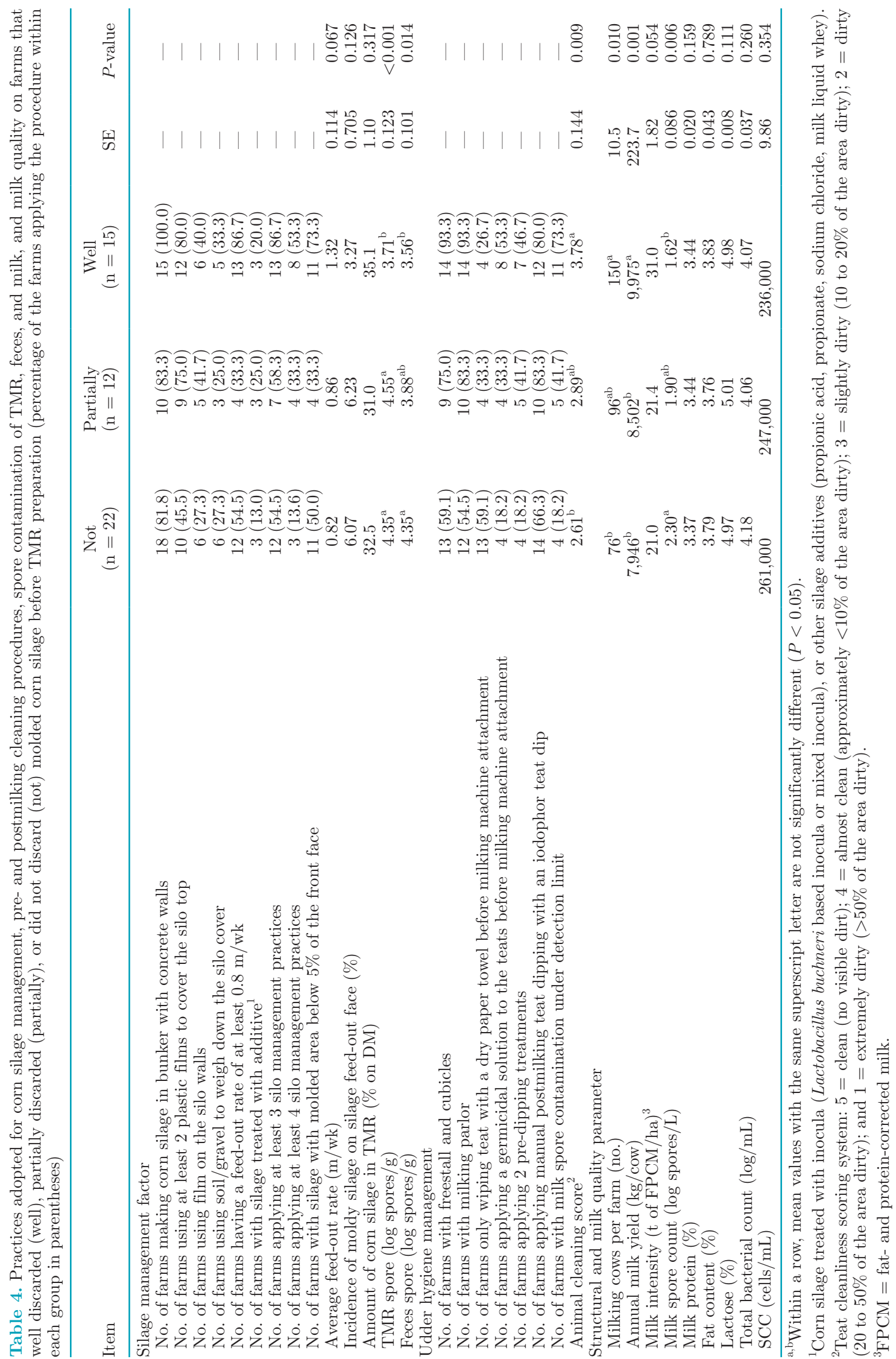


Table 5. Pearson correlation coefficients of milk spore contamination, silo face visibly molded, TMR and feces spore contamination, and animal cleaning score on the 49 dairy farms ${ }^{1}$

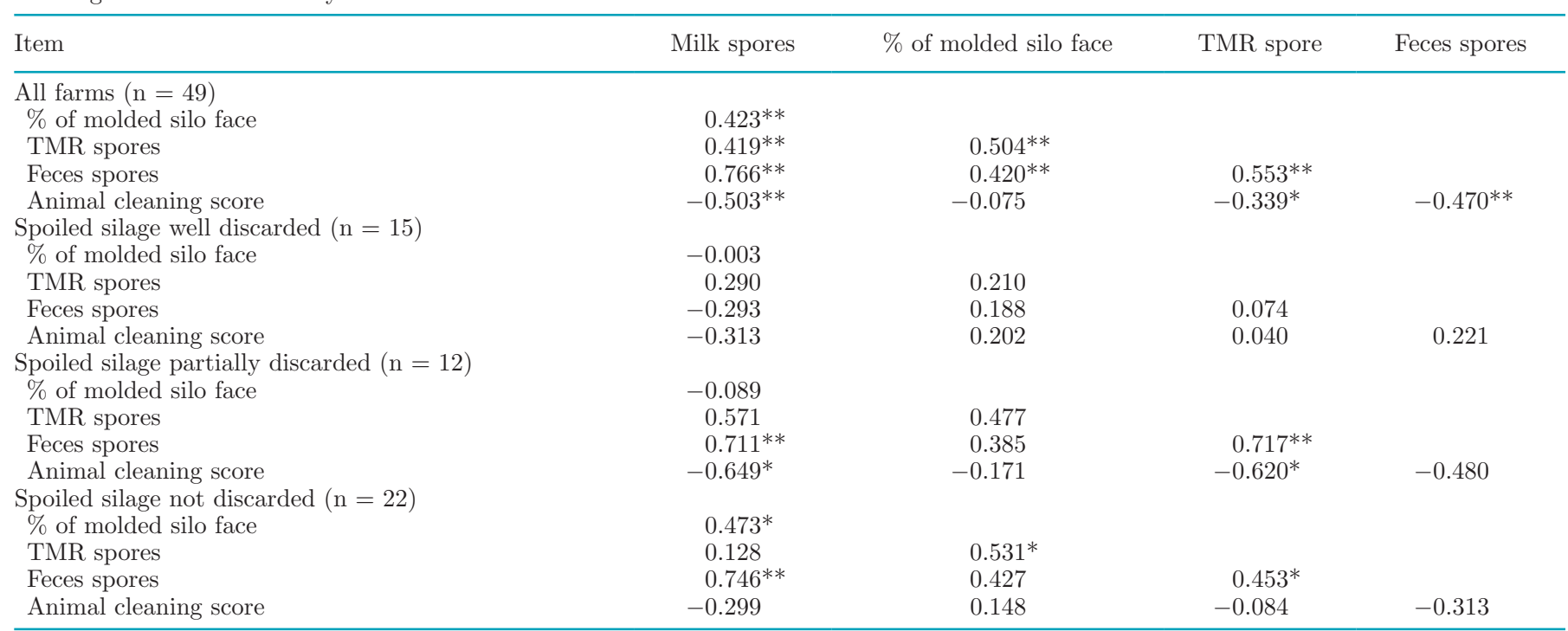

${ }^{1}$ Data are reported aggregated or split out by farms that well, partially, or do not discard corn spoiled silage before TMR preparation.

${ }^{*} P<0.05 ;{ }^{* *} P<0.01$.

age of molded silo face and the feces spore count. A relation between the percentage of molded silo face, and spores in the TMR and feces was also determined. No significant effect was found for the analyzed parameters on farms that discarded the molded silages completely before TMR preparation.

\section{DISCUSSION}

Recent evidence from several milk production chains for PDO cheeses, milk powder, and long conservation pasteurized milk throughout the world has pointed out the need to reduce the sporeformer contamination of bulk tank milk to a minimum because of the difficulties in reducing their contamination level later on in the dairy plant, in part due to the fact that milk heat treatments exacerbate the activation of spore germination (Doyle et al., 2015; Masiello et al., 2017).

This study has analyzed the contamination pathways of anaerobic and facultative anaerobic sporeformers, from silage to bulk tank milk, on 49 dairy farms in northern Italy that produce milk destined for Grana Padano PDO cheese, and has coupled the plate count method with 16S-DNA sequencing of the dominant isolated anaerobic and facultative anaerobic sporeformer species.

In the present experiment, the low contaminated silages presented a very similar anaerobic and facultative anaerobic spore population to those of the considered soil samples. Most of the species observed in the soil (7 vs. 11) were found in both the well-conserved silage (with low $\mathrm{pH}$, high lactic acid content, and an absence of butyric acid) and in the deteriorated silage. However, most of the samples from the peripheral areas of the corn silage, which were found to be aerobically spoiled, had a higher number of anaerobic and facultative anaerobic spores that was several magnitudes higher (up to $7.76 \log$ spores/g) than the core samples. The dominant Clostridium and Paenibacillus species in the spoiled samples were C. aerotolerans, $C$. celerecrescens, C. jejuense, C. sporogenes, C. tyrobutyricum, C.xylanolyticum, $P$. macerans, and $P$. thermophilus. This suggests that these species have the capacity to outgrow in silage during aerobic deterioration, as previously suggested for C. tyrobutyricum in grass silage (Jonsson, 1991). Other authors (Vissers et al., 2007a; Borreani and Tabacco, 2008) suggested, on the basis of tests conducted with the most probable number (MPN) method, that the aerobic deterioration of corn silage led to an increase in butyric acid bacteria, which in turn produced gas under anaerobiosis on lactate acetate agar. Borreani et al. (2013), in trials on the deterioration of corn silage, then found the outgrowth of Paenibacillus macerans, which was identified by 16S-DNA sequencing as the dominant anaerobic and facultative anaerobic sporeformer isolated on an RCM medium. Driehuis et al. (2016) found C. tyrobutyricum, C. beijerinckii, and Paenibacillus spp. (identified by means of a PCR assay on C. tyrobutyricum, C. beijerinckii, and Paenibacillus spp.) as the dominant species, in both low and highly contaminated corn silage (less or more than $4 \log \mathrm{MPN} / \mathrm{g})$. This result was achieved using 
MPN tubes in which gas formation was observed in a Van Beynum and Pette medium. Zucali et al. (2015), in a survey on 23 dairy farms in northern Italy, reported the presence of $C$. tyrobutyricum, $C$. beijerinckii, $C$. butyricum, and $C$. sporogenes in corn. This result was achieved using a multiplex PCR of colonies purified from MPN gas positive tubes (lactate-acetate agar plus reconstituted skim milk). In the present study, $C$. beijerinckii was not found among the dominant anaerobic and facultative anaerobic sporeformers in any of the corn silage samples, even though it was present in some of the TMR fed to dairy cows. The contrasting results between the present study and the studies of Zucali et al. (2015) and Driehuis et al. (2016) about the presence of $C$. beijerinckii among the dominant anaerobic sporeformers in corn silage could be due to the MPN medium, containing lactate acetate, that was used in those studies, which could have favored a selective multiplication of saccharolytic clostridia.

Most of the dominant sporeformer species in the low contaminated TMR (below $3.0 \mathrm{log}$ spores/g) were found to belong to C. tyrobutyricum, C. beijerinckii, and $P$. macerans. The higher contaminated TMR (>3.0 log spores/g) instead showed less incidence of C. tyrobutyricum and P. macerans and an equal presence of $C$. beijerinckii. Furthermore, C. aerotolerans, C. butyricum, C. celerecrescens, C. xylanolyticum, and $P$. thermophilus were among the dominant isolated species. The frequency of most of these clostridia species (except $C$. aerotolerans) increased in the highly contaminated TMR (>5.0 log spores/g), and it seems that $P$. thermophilus partially substituted $P$. macerans.

No Clostridium species were found in milk with a higher spore count than 1,000 spores/L. All the identified anaerobic and facultative anaerobic species belonged to Paenibacillus spp., with P. macerans and $P$. thermophilus representing $62 \%$ of the sporeformer population. This result could be connected to the isolation of colonies from the plates that selected only the dominant population; therefore, the clostridia presence at a lower level cannot be excluded. The reason why Paenibacillus species dominate bulk tank milk of farms with spore count higher than $3 \log$ spores/L still remains unexplainable with the data obtained in this study. Bermúdez et al. (2016) found, on 5 commercial dairy plants in Uruguay, that $C$. tyrobutyricum was the most frequently isolated species in milk (ranging from 50 to $58 \%$ ), C. sporogenes was the second (17 to $21 \%$ ), whereas $C$. beijerinckii and C. butyricum were present at lower levels, and they also observed several other species of clostridia, that is, C. bifermentans, C. acetobutylicum, C. xylanolyticum, and C. aminovalericum. Masiello et al. (2017), in a longitudinal assessment of dairy farms in New York State, found that Paenibacil- lus spp. was widely present in bulk tank milk. Paenibacillus spp. (which is a facultative anaerobe) is one of the main sporeformer genera that limits the shelf life of pasteurized fluid milk under refrigeration (Masiello et al., 2017).

Clostridium spp. that were most frequently identified in the different matrices considered in the present research belonged to 2 clusters (I and XIVa), according to the classification proposed by Collins et al. (1994). Cluster I is a family of Clostridiaceae, which included the following identified species: C. tyrobutyricum, $C$. beijerinckii, C. butyricum (in the group of nonliquefying gelatin), and C. sporogenes and C. acetobutylicum (liquefying gelatin). The XIVa family cluster of Ruminococcaceae included the following species: C. aerotolerans, C. aminovalericum, C. celerecrescens, C. xylanolyticum (Collins et al., 1994), and C. jejuense (Jeong et al., 2004). Clostridium aerotolerans, C. celerecrescens, and C. xylanolyticum are able to hydrolyze and then hydrogenate hydroxycinnamic acids (ferulic and p-coumaric acids), which are esterified to arabinoxylan in plant cell walls and are thus involved in the anaerobic biotransformation of the fiber components linked to lignin (Chamkha et al., 2001). Furthermore, C. xylanolyticum is also able to utilize a wide range of carbohydrates and lactate as an energy source. In the present study, these Clostridium species were commonly identified in soil, deteriorated corn silages, and feces samples. It can be speculated that these species are involved in the advanced degradation of OM in deteriorated silages together with filamentous fungi. The $\mathrm{pH}$ is not too acidic (around 6.0) in these silages, the temperature is around $37^{\circ} \mathrm{C}$, and there is a limited availability of oxidizable free soluble nutrients, such as organic acids and sugars. Therefore, the main sources of substrate for microbial growth are linked to the structural carbohydrates of fiber, which are less available due to cell wall lignification (McSweeney et al., 1999). Phenolic acids are ester-linked to arabinoxylan and lignin, or cross-linked to lignin and polysaccharide through ether and ester bonds, respectively. It is thought that the ester linkages between phenolic acids and polysaccharide limit the anaerobic degradation of fiber through the microorganisms in the gut of ruminants, and these groups of clostridia share a role in the degradation of fiber in the gastrointestinal tract of cows (Dowd et al., 2008).

The role of corn silage management in increasing the risk of bulk tank milk contamination from anaerobic and facultative anaerobic spores has been analyzed in detail on 49 commercial dairy farms. It has been stated, in recent farm surveys, that corn silage is the main source of the anaerobic and facultative anaerobic spore contamination of TMR, in particular when aerobically spoiled areas are included during feed-out (Tabacco 
and Borreani, 2002; Vissers et al., 2007c; Driehuis et al., 2016). The present research has shown a high variability in the anaerobic and facultative anaerobic spore counts in the different studied matrices, with greater values being observed in samples from the peripheral areas of corn silage, especially when aerobic deterioration had taken place. Most of the forage conserved in the core mass of the silo ( $75 \%$ of the farms) contained lower numbers of spores than $3.0 \mathrm{log}$ spores/g. This unavoidable contamination has mainly been attributed to soil contamination during corn growth and harvesting (Julien et al., 2008). The passage of spores from manured soil to silage has been proved in several studies on grass silage, and many of these studies related clostridia spore contamination to the slurry application timing, rates, and methods (e.g., Östling and Lindgren, 1991; Davies et al., 1996). Östling and Lindgren (1991) enumerated the clostridia in manure and in manured crops used for silage and found clostridia counts of around $4.2 \mathrm{log}$ spores/g in manure, a number that decreased by $83 \%$ in grass silage crops at harvesting. Lango and Heinonen-Tanski (1995), in a work on cattle slurry on Finnish dairy farms, reported that the occurrence of Clostridium tyrobutyricum spores in an anaerobic and facultative anaerobic sporeformer population was unexpectedly low (around 5\%).

In the present study, the TMR spore count was found to be influenced by the amount of deteriorated corn silage that was included in the TMR during feed-out and preparation. Figure 4 clearly suggests this hypothesis: the spore count of TMR increased as the incidence of spoiled corn silage (visible moldy silage) present in the silo increased, and it was also connected to the care taken in cleaning the spoiled silage before feed-out. Most of the farms (9 out of 13 farms) that coupled a good silage management, to prevent the presence of spoiled silage in their silos (below $5 \%$ of the silage front face), with a careful discarding of all the molded spots, were able to keep their TMR spore counts below 4.0 $\log$ spores/g.

The influence of TMR on the anaerobic and facultative anaerobic spore content in the feces of dairy cows indicates that the feces presented a greater contamination than $3.0 \log$ spores/g when the TMR spore count was greater than $4.5 \mathrm{log}$ spores/g. Nineteen farms out of the 21 that had feces contaminations with more than $4.0 \log$ spores/g did not clean the silo face properly before feed-out, and the majority of them (18 out of 19) presented a higher TMR spore count than 4.0 log spores/g. A higher concentration in feces than in TMR is generally explained by the digestion of feed components during passage through the intestinal tract (Driehuis, 2013). Driehuis et al. (2016) reported a ratio between spores in feces and in TMR of around 3. In the present study, 4 farms showed a ratio higher than 4 between the spores in the feces and the spores in the TMR. This large increase in spores in the feces (feces/ TMR spore ratio from 14 to 59) could be explained, not only by sampling problems that could have led to an overestimation of the feces spore count on these farms, but also by a multiplication of clostridia in the digestive tracts, as previously suggested by Contrepois et al. (1971). It has recently been reported that clostridia generally account for approximately $20 \%$ of the total microbial population in the intestinal tract of cattle (Dowd et al., 2008; Callaway et al., 2010) and can become problematic in the case of dietary stress, injury, changes in management, parasitism, or other unusual circumstances (McGuirk, 2015). Therefore, new roles of clostridia in the intestinal tract may be speculated and would suggest their beneficial function in improving the digestion of complex OM, such as cellulose (Dowd et al., 2008).

The passage of spores into milk occurs from the exterior of the cow's teats, through feces contamination, and they are transferred to milk during the milking process (Vissers at al., 2007c). Therefore, the critical points are feces spore contamination and the accuracy of the cleaning routines during milking (Vissers at al., 2007c; Zucali et al., 2015).

The data of the present study have confirmed the role of feces in spore milk contamination and the role of management practices to reduce the risk of carryover of spores from spoiled corn silages to milk. In particular, a positive correlation was found between milk spore count in farms that did not discard molded silages before TMR preparation and feces spore count. There is clear evidence that the majority of farms that discarded spoiled silages well before feed-out also adopted management practices that were considered to be effective in reducing silage spoilage and the carryover of anaerobic and facultative anaerobic spores from feeds to milk, with more than $70 \%$ of the farms having milk spore contamination values under the detection limit. On the other hand, more than $50 \%$ of the farms that partially discarded or did not discard spoiled silage failed to reach this goal (Table 4). The silage management practices (such as corn silage conserved in a bunker with concrete walls, at least 2 plastic films used to cover the silo top, plastic film on the silo walls, and a feed-out rate of at least $0.8 \mathrm{~m} / \mathrm{wk}$ ) helped to reduce the incidence of aerobic deterioration (Borreani et al., 2018), and consequently, the reduction of the discarded spoiled silage led to lower spore contamination of the TMR, feces, and milk. It is also evident that farms that carried out cleaning management procedures before 
silage feeding also adopted pre- and postmilking procedures to reduce the risk of microbial contamination of milk during milking.

The present data have confirmed that the anaerobic and facultative anaerobic spore count of milk is influenced to a great extent by the inclusion of aerobically deteriorated corn silage in TMR. This leads to the conclusion that it is not the presence of silage itself in the TMR that increases the risk of milk contamination, but the undervalued capability of aerobic deteriorated silage to contaminate the TMR. When spoiled silage is included in the TMR, it contributes to a great extent to increasing the spore content of TMR and consequently to increasing the risk of a higher feces spore count. This makes any further control of spore contamination along the milk production chain very difficult, even when the milking and cleaning practices are done properly. Processing milk to reduce spore contamination in dairy plants is expensive, time consuming, and labor intensive, and even though it is impossible to eliminate the risk of spore contamination of milk on farms, the results of this work show that it is possible to reduce this risk through the implementation of good farm management practices and specific processing steps from silage to milking.

\section{ACKNOWLEDGMENTS}

The authors thank Simona Avattaneo (Associazione Regionale Allevatori del Piemonte, ARAP, Cuneo, Italy) for help in microbiological analyses. This work was funded by the Italian Ministry delle Politiche Agricole, Alimentari e Forestali (MIPAAF) national project "FILIGRANA" DM 25741/7303/11 "Valorizzazione della produzione del Grana Padano DOP tramite il controllo di filiera e l'ottimizzazione dei processi produttivi."

\section{REFERENCES}

Bergère, J. L., and S. Sivelä. 1990. Detection and enumeration of clostridial spores related to cheese quality - Classical and new methods. Bulletin IDF, n. 251, International Dairy Federation, Bruxelles, Belgium, pp. 18-23.

Bermúdez, J., M. J. González, J. A. Olivera, J. A. Burgueño, P. Juliano, E. M. Fox, and S. M. Reginensi. 2016. Seasonal occurrence and molecular diversity of clostridia species spores along cheesemaking streams of 5 commercial dairy plants. J. Dairy Sci. 99:3358-3366. https://doi.org/10.3168/jds.2015-10079.

Borreani, G., P. Dolci, E. Tabacco, and L. Cocolin. 2013. Aerobic deterioration stimulates outgrowth of spore-forming Paenibacillus in corn silage stored under oxygen-barrier or polyethylene films. J. Dairy Sci. 96:5206-5216. https://doi.org/10.3168/jds.2013-6649.

Borreani, G., and E. Tabacco. 2008. Low permeability to oxygen of a new barrier film prevents butyric acid bacteria spore formation in farm corn silage. J. Dairy Sci. 91:4272-4281. https://doi.org/10 $.3168 /$ jds.2008-1151.
Borreani, G., and E. Tabacco. 2010. The relationship of silage temperature with the microbiological status of the face of corn silage bunkers. J. Dairy Sci. 93:2620-2629. https://doi.org/10.3168/jds .2009-2919.

Borreani, G., and E. Tabacco. 2014. Improving corn silage quality in the top layer of farm bunker silos through the use of a next-generation barrier film with high impermeability to oxygen. J. Dairy Sci. 97:2415-2426. https://doi.org/10.3168/jds.2013-7632.

Borreani, G., E. Tabacco, R. J. Schmidt, B. J. Holmes, and R. E Muck. 2018. Silage review: Factors affecting dry matter and quality losses in silages. J. Dairy Sci. 101:3952-3979. https://doi.org/ $10.3168 /$ jds.2017-13837.

Bottazzi, V., and B. Battistotti. 1978. Indicazioni per il controllo del gonfiore tardivo del formaggio Grana (Indication to control late blowing of Grana cheese). Scienza Lattiero Casearia 25:313-325.

Callaway, T. R., S. E. Dowd, T. S. Edrington, R. C. Anderson, N. Krueger, N. Bauer, P. J. Kononoff, and D. J. Nisbet. 2010. Evaluation of bacterial diversity in the rumen and feces of cattle fed different levels of dried distillers grains plus solubles using bacterial tag-encoded FLX amplicon pyrosequencing. J. Anim. Sci. 88:3977-3983. https://doi.org/10.2527/jas.2010-2900.

Canale, A., M. E. Valente, and A. Ciotti. 1984. Determination of volatile carboxylic acids (C1-C5) and lactic acid in aqueous acid extracts of silage by high performance liquid chromatography. J. Sci. Food Agric. 35:1178-1182.

Chamkha, M., J.-L. Garcia, and M. Laba. 2001. Metabolism of cinnamic acids by some Clostridiales and emendation of the descriptions of Clostridium aerotolerans, Clostridium celerecrescens and Clostridium xylanolyticum. Int. J. Syst. Evol. Microbiol. 51:21052111. https://doi.org/10.1099/00207713-51-6-2105.

Collins, M. D., P. A. Lawson, A. Willems, J. J. Cordoba, J. FernandezGarayzabal, P. Garcia, J. Cai, H. Hippe, and J. A. E. Farrow. 1994. The phylogeny of the genus Clostridium: Proposal of five new genera and eleven new species combinations. Int. J. Syst. Bacteriol. 44:812-826.

Colombari, G., G. Borreani, and G. M. Crovetto. 2001. Effect of ensiling alfalfa at low and high dry matter on production of milk used to make Grana cheese. J. Dairy Sci. 84:2494-2502. https://doi .org/10.3168/jds.S0022-0302(01)74700-5.

Contrepois, M., P. Gouet, and D. Sauvant. 1971. Comportement des spores de bactéries anaérobies fermentant le lactate dans le tractus digestif du ruminant. II. Évolution du nombre de spores de $C$. tyrobutyricum introduites au niveau du rumen, au cours du transit digestif chez le ruminant. Ann. Biol. Anim. Biochim. Biophys. 11:139-154.

Davies, D. R., R. J. Merry, and E. L. Bakewell. 1996. The effect of timing of slurry application on the microflora of grass, and changes occurring during silage fermentation. Grass Forage Sci. 51:42-51.

Dowd, S. E., T. R. Callaway, R. D. Wolcott, Y. Sun, T. McKeehan, R. G. Hagevoort, and T. S. Edrington. 2008. Evaluation of the bacterial diversity in the feces of cattle using $16 \mathrm{~S}$ rDNA bacterial tag-encoded FLX amplicon pyrosequencing (bTEFAP). BMC Microbiol. 8:125-132. https://doi.org/10.1186/1471-2180-8-125.

Doyle, C. J., D. Gleeson, K. Jordan, T. P. Beresford, R. P. Ross, G. F. Fitzgerald, and P. D. Cotter. 2015. Anaerobic sporeformers and their significance with respect to milk and dairy products. Int. J. Food Microbiol. 197:77-87. https://doi.org/10.1016/j.ijfoodmicro .2014 .12 .022 .

Driehuis, F. 2013. Silage and the safety and quality of dairy foods: A review. Agric. Food Sci. 22:16-34. https://doi.org/10.23986/afsci 6699 .

Driehuis, F., J. Hoolwerf, and J. L. W. Rademaker. 2016. Concurrence of spores of Clostridium tyrobutyricum, Clostridium beijerinckii and Paenibacillus polymyxa in silage, dairy cow faeces and raw milk. Int. Dairy J. 63:70-77. https://doi.org/10.1016/j.idairyj .2016.08.004.

Durak, Z., H. Fromm, J. Huck, R. Zadoks, and K. J. Boor. 2006. Development of molecular typing methods for Bacillus spp. and Paenibacillus spp. isolated from fluid milk products. J. Food Sci. 71:M50-M56. https://doi.org/10.1111/j.1365-2621.2006.tb08907 .x. 
Hall, L., K. A. Doerr, S. L. Wohlfiel, and G. D. Roberts. 2003. Evaluation of the MicroSeq system for identification of mycobacteria by $16 \mathrm{~S}$ ribosomal DNA sequencing and its integration into a routine clinical mycobacteriology laboratory. J. Clin. Microbiol. 41:14471453.

Ivy, R. A., M. L. Ranieri, N. H. Martin, H. C. den Bakker, B. M. Xavier, M. Wiedmann, and K. J. Boor. 2012. Identification and characterization of psychrotolerant sporeformers associated with fluid milk production and processing. Appl. Environ. Microbiol. 78:1853-1864. https://doi.org/10.1128/AEM.06536-11.

Jeong, H., H. Yi, Y. Sekiguchi, M. Muramatsu, Y. Kamagata, and J. Chun. 2004. Clostridium jejuense sp. nov., isolated from soil. Int. J. Syst. Evol. Microbiol. 54:1465-1468. https://doi.org/10.1099/ ijs. $0.63128-0$.

Jonsson, A. 1989. The role of yeasts and clostridia in silage deterioration. PhD Diss., Swedish University of Agricultural Science. Report 42 . Uppsala, Sweden.

Jonsson, A. 1990. Enumeration and confirmation of Clostridium tyrobutyricum in silages using neutral red, D-cycloserine and lactate dehydrogenase activity. J. Dairy Sci. 73:719-725.

Jonsson, A. 1991. Growth of Clostridium tyrobutyricum during fermentation and aerobic deterioration of grass silage. J. Sci. Food Agric. 54:557-568.

Julien, M.-C., P. Dion, C. Lafrenière, H. Antoun, and P. Drouin. 2008. Sources of clostridia in raw milk on farms. Appl. Environ. Microbiol. 74:6348-6357. https://doi.org/10.1128/AEM.00913-08.

Klijn, N., F. F. J. Nieuwenhof, J. D. Hoolwerf, C. B. V. D. Waals, and A. H. Weerkamp. 1995. Identification of Clostridium tyrobutyricum as the causative agent of late blowing in cheese by species specific PCR amplification. Appl. Environ. Microbiol. 61:2919-2924.

Lango, Z., and H. Heinonentanski. 1995. Occurrence of Clostridium tyrobutyricum in cattle slurry and fresh forage grasses. Bioresour. Technol. 53:189-191.

Le Bourhis, A. G., J. Doré, J. P. Carlier, J. F. Chamba, M. R. Popoff, and J. L. Tholozan. 2007. Contribution of C. beijerinckii and $C$. sporogenes in association with $C$. tyrobutyricum to the butyric fermentation in Emmental type cheese. Int. J. Food Microbiol. 113:154-163. https://doi.org/10.1016/j.ijfoodmicro.2006.06.027.

Le Bourhis, A. G., K. Saunier, J. Doré, J. P. Carlier, J. F. Chamba, M. R. Popoff, and J.-L. Tholozan. 2005. Development and validation of PCR primers to assess the diversity of Clostridium spp. in cheese. Appl. Environ. Microbiol. 71:29-38. https://doi.org/10 .1128/AEM.71.1.29-38.2005.

Masiello, S. N., D. Kent, N. H. Martin, Y. H. Schukken, M. Wiedmann, and K. J. Boor. 2017. Longitudinal assessment of dairy farm management practices associated with the presence of psychrotolerant Bacillales spores in bulk tank milk on 10 New York State dairy farms. J. Dairy Sci. 100:8783-8795. https://doi.org/10 $.3168 /$ jds.2017-13139.

McGuirk, S. M. 2015. Managing clostridial diseases in cattle. University of Wisconsin, School of Veterinary Medicine, Madison, US. Accessed Feb. 4, 2019. https://www.vetmed.wisc.edu/dms/fapm/ fapmtools/7health/manage-clostridial.pdf.
McSweeney, C. S., A. Dulieu, R. I. Webb, T. Del Dot, and L. L. Blackall. 1999. Isolation and characterization of a Clostridium sp. with cinnamoyl esterase activity and unusual cell envelope ultrastructure. Arch. Microbiol. 172:139-149.

Östling, C. E., and S. E. Lindgren. 1991. Bacteria in manure and on manured and NPK-fertilised silage crops. J. Sci. Food Agric. 55:579-588.

Stadhouders, J., G. Hup, and F. F. J. Nieuwenhof. 1983. Silage and cheese quality. NIZO mededeling M19A. Netherlands Institute for Dairy Research, Ede, the Netherlands.

Stadhouders, J., and K. Jørgensen. 1990. Prevention of the contamination of raw milk by a hygienic milk production. Bull. Int. Dairy Fed. 251:31-35.

Stadhouders, J., and S. F. Spoelstra. 1990. Prevention of the contamination of raw milk by making a good silage. Bull. Int. Dairy Fed. 251:24-31.

Tabacco, E., and G. Borreani. 2002. Extent of aerobic deterioration in farm maize silage as affected by silo management. Pages 178-179 in Proc. 13th International Silage Conference, Auchincruive, Scotland. SAC, Auchincruive, Scotland, UK.

Tabacco, E., S. Piano, L. Cavallarin, T. F. Bernardes, and G. Borreani. 2009. Clostridia spore formation during aerobic deterioration of maize and sorghum silages as influenced by Lactobacillus buchneri and Lactobacillus plantarum inoculants. J. Appl. Microbiol. 107:1632-1641. https://doi.org/10.1111/j.1365-2672.2009.04344.x.

te Giffel, M. C., A. Wagendorp, A. Herrewegh, and F. Driehuis. 2002 Bacterial spores in silage and raw milk. Antonie van Leeuwenhoek 81:625-630.

Vissers, M. M. M., F. Driehuis, M. C. te Giffel, P. De Jong, and J. M. G. Lankveld. 2007a. Concentrations of butyric acid bacteria spores in silage and relationships with aerobic deterioration. J. Dairy Sci. 90:928-936. https://doi.org/10.3168/jds.S0022-0302(07)71576-X.

Vissers, M. M. M., F. Driehuis, M. C. te Giffel, P. De Jong, and J. M. G. Lankveld. 2007b. Quantification of the transmission of microorganisms to milk via dirt attached to the exterior of teats. J. Dairy Sci. 90:3579-3582. https://doi.org/10.3168/jds.2006-633.

Vissers, M. M. M., F. Driehuis, M. C. te Giffel, P. De Jong, and J. M. G. Lankveld. 2007c. Minimizing the level of butyric acid bacteria spores in farm tank milk. J. Dairy Sci. 90:3278-3285. https://doi .org/10.3168/jds.2006-798.

Walstra, P., J. T. M. Wouters, and T. J. Geurts. 2005. Dairy Science and Technology. 2nd ed. Taylor and Francis, New York, NY.

Wells-Bennik, M. H. J., F. Driehuis, and S. A. F. T. van Hijum. 2016. Prospects for improved control of dairy-relevant sporeformers using -omics technologies. Curr. Opin. Food Sci. 10:38-44. https:// doi.org/10.1016/j.cofs.2016.08.005.

Zucali, M., L. Bava, S. Colombini, M. Brasca, M. Decimo, S. Morandi, A. Tamburini, and G. M. Crovetto. 2015. Management practices and forage quality affecting the contamination of milk with anaerobic spore-forming bacteria. J. Sci. Food Agric. 95:1294-1302. https://doi.org/10.1002/jsfa.6822. 